Viso - Cadernos de estética aplicada Revista eletrônica de estética

ISSN 1981-4062

NN 9, jul-dez/2010

http://www.revistaviso.com.br/

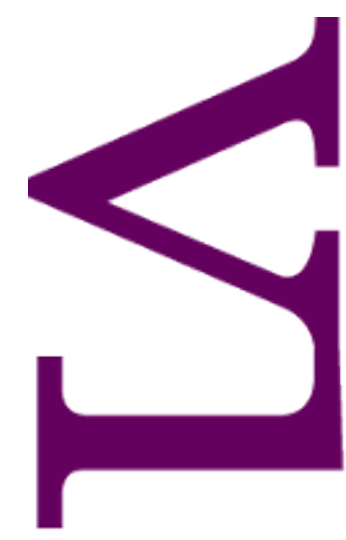

\title{
A bela alma e a estética goethiana do símbolo Wilma Patricia Maas
}

Universidade Estadual Paulista (UNESP) 


\section{RESUMO}

\section{A bela alma e a estética goethiana do símbolo}

Pretende-se acompanhar o desenvolvimento do pensamento estético de Goethe entre os anos de 1780 e 1790 paralelamente a sua expressão no livro VI do romance Os anos de aprendizado de Wilhelm Meister (1795-1796), no qual se narra a trajetória da Bela Alma em direção ao progressivo abandono dos símbolos religiosos como suporte sensível da fé. Entende-se que a convivência de Goethe com Karl Philipp Moritz foi decisiva para a concepção dos ensaios "Sobre os objetos das artes plásticas" (1797) e "Imitação simples, maneira, estilo" (1789), fundamentais para a constituição do pensamento estético de Goethe à época.

Palavras-chave: Goethe - Bela Alma - Karl Philipp Moritz - símbolo - imitação

\section{ABSTRACT}

\section{The "Beautiful Soul" and Goethe's Aesthetics of Symbol}

We want to follow the development of Goethe's aesthetical thinking between 1780 and 1790 as configured in Book VI of Goethe's Novel Wilhelm Meister's Apprenticeship Years (1795-1796), where the path of the Beautiful Soul towards the progressive abandon of religious symbols as sensuous support for faith is narrated. We understand that Goethe's acquaintance with Karl Philipp Moritz in Rome played a major part in the conception of "On the Objects of the Plastic Arts" (1797) and "Simple Imitation of Nature, Manner, Stile" (1789), both fundamental texts for the comprehension of Goethe's aesthetical thinking by that time.

Keywords: Goethe - Beautiful Soul - Karl Philipp Moritz - symbol - imitation 


\section{MAAS, W. P. "A bela alma e a estética goethiana do símbolo". In: Viso: Cadernos de estética aplicada, v. IV, n. 9 (jul-dez/2010), pp. 136-146}

DOI: 10.22409/1981-4062/v9i/106

Aprovado: 26.07.2011. Publicado: 17.08.2011.

(C) 2011 Wilma Patricia Maas. Esse documento é distribuído nos termos da licença Creative Commons Atribuição-NãoComercial 4.0 Internacional (CC-BY-NC), que permite, exceto para fins comerciais, copiar e redistribuir o material em qualquer formato ou meio, bem como remixá-lo, transformá-lo ou criar a partir dele, desde que seja dado o devido crédito e indicada a licença sob a qual ele foi originalmente publicado.

Licença: http://creativecommons.org/licenses/by-nc/4.0/deed.pt_BR

Accepted: 26.07.2011. Published: 17.08.2011.

(C) 2011 Wilma Patricia Maas. This document is distributed under the terms of a Creative Commons Attribution-NonCommercial 4.0 International license (CC-BY-NC) which allows, except for commercial purposes, to copy and redistribute the material in any medium or format and to remix, transform, and build upon the material, provided the original work is properly cited and states its license.

License: http://creativecommons.org/licenses/by-nc/4.0/ 
O livro VI do romance de Goethe Os anos de aprendizado de Wilhelm Meister (17951796) tem sido considerado como um excurso, uma peça que não se encaixa na arquitetura do romance como um todo. "As confissões da Bela Alma" são a narrativa autobiográfica de um processo de conversão, não apenas da conversão de uma jovem que toma distância dos prazeres mundanos e da impressão dos sentidos em direção ao "invisível", mas também do processo de progressivo distanciamento do luteranismo dominante na Alemanha do século XVIII em favor de uma relação mais mística e mais pessoal com Deus. Ao mesmo tempo, a narrativa da Bela Alma permitirá que se contemplem alguns princípios da estética goethiana desenvolvida no período de 1770 a 1797, na qual têm papel predominante os conceitos de símbolo e de imitação formadora do Belo. No âmbito deste texto, importa mostrar que a redenção encontrada pela Bela Alma no romance de 1796 segue muito de perto a própria construção do conceito de símbolo artístico em Goethe, em sua trajetória desde um ponto de vista místico, relacionado às primeiras leituras sobre alquimia, até a elaboração de seu conceito "clássico" de símbolo, no ensaio "Sobre os objetos das artes plásticas" [Über die Gegenstände der bildenden Künste], de 1797.

Se, por um lado, a concepção de símbolo em Goethe é devedora de suas relações com Susanna von Klettenberg, a amiga de Goethe simpatizante do pietismo que teria servido de modelo à concepção da Bela Alma, é, por outro lado, devedora também do contato pessoal de Goethe com Karl Philipp Moritz, durante a temporada romana (1786-1788). O ensaio de Moritz Über die bildende Nachahmung des Schönen [Sobre a imitação formadora do belo], de 1788, entende a atividade artística como uma atividade essencialmente produtora, levada a cabo por uma "thätige Kraft" (força produtiva) que prescinde das características do objeto singular em nome da imitação formadora do "Belo mais elevado", para além da esfera do sensível. Na narrativa da Bela Alma, essa concepção está associada à perspectiva da busca pela fé, sob a forma do questionamento da necessidade da mediação do sensível para que se manifeste a revelação. Esta se dará por meio da arte, mais especificamente, da arte proposta pelo Classicismo de Weimar, como se pretende demonstrar aqui.

Klettenberg, culta e instruída também nas ciências naturais, foi a amiga que recomendou a Goethe a leitura da Opus Mago-Cabbalisticum, de Georg von Welling (1735), obra da alquimia na qual se defende a tese de como "a natureza pode ser contemplada e reconhecida a partir de Deus e como Deus pode ser visto e reconhecido na natureza". ${ }^{1}$ As conseqüências de tais leituras na estética goethiana não demoram a se fazer notar.

Ainda que o jovem Goethe não tenha teorizado expressamente sobre o símbolo, já nas Ephemeriden de 1770 deparamo-nos com uma afirmação que estará na base de seu pensamento estético: "A arte nada mais é do que a luz da natureza". ${ }^{2}$ Essa afirmação comprova a tradução das concepções místicas e alquímicas da natureza para o âmbito da arte. Goethe desenvolve sua simbólica a partir desse deslocamento. É por meio da arte que se revela o divino oculto na natureza das coisas. Em um texto de 1776, 
encontra-se a expressão que esclarece, de maneira exemplar, esse neoplatonismo, que resultará mais tarde no conceito artístico de símbolo:

Ela [a forma] é decididamente o espelho por meio do qual recolhemos ao coração do homem os sagrados raios da ampla natureza em um foco de luz. Mas o espelho, apenas! Aqueles a quem não foi dado, jamais o possuirão. ${ }^{3}$

A forma, que "baixa no mundo físico", como disse Todorov, é o espelho que recolhe e dirige os raios sagrados da Natureza ao coração do homem. Mas ela é "apenas" um pedaço de vidro, um veículo. O processo é misterioso e arbitrário, não depende de qualquer ato voluntário e mecânico do artista.

No texto de 1797 Goethe propõe inicialmente uma tipologia dos objetos artísticos, divididos entre "naturais", "ideais" e objetos "que não seriam em si e para si compreensíveis ou interessantes" ${ }^{\text {, }}$ mas que só podem ser apreciados quando incluídos em uma sequência, visual ou narrativa. Como naturais, Goethe classifica aqueles objetos que representam "coisas conhecidas, comuns, ordinárias, tais como são [...]" ${ }^{5}$, mesmo quando elevados ao estatuto de um todo artístico. Produzidos pela natureza, tais objetos são elevados a objetos artísticos pelo trabalho mecânico do artista. Já os objetos ideais [idealische] não são tomado em si mesmos, mas afetam-nos, em sua elevação, despidos de todo caráter vulgar e individual. Não se tornam obras de arte por meio da elaboração do artista, mas sim se apresentam a ele "como um objeto perfeita e completamente construído" [vollkommen gebildeter Gegenstand]. Distinguem-se dos objetos naturais ainda porque são "produzidos pelo espírito do homem, na mais íntima relação com a Natureza". ${ }^{6}$

Ao final da classificação dos objetos artísticos, Goethe propõe então o deslocamento da perspectiva a partir dos objetos em direção a uma concepção da arte como resultado da força produtiva do artista, do tratamento dado ao objeto por seu espírito, e não da mera capacidade de imitação:

Se em todas as elaborações artísticas o objeto [Gegenstand] nunca pode ser considerado isoladamente, mas na medida em que é manejado, podemos contudo dizer dos três gêneros agora descritos que eles são particularmente considerados em relação ao objeto [Objekt]. Nos gêneros que se seguem será mais considerado o tratamento e o espírito daquele que trata do objeto [...]. ${ }^{7}$

Pode-se reconhecer aí a virada copernicana do autor, que desloca a determinação da obra de arte do campo do objeto para o campo da produção, ou seja, do espírito que cria. O símbólico é resultado assim do tratamento dado ao objeto, ou melhor ainda, da qualidade do afeto que comove o artista, um "sentimento profundo", que, coincidindo com "os melhores e supremos objetos [...], no melhor dos casos, os fará simbólicos". ${ }^{8} \mathrm{O}$ termo "simbólico" tem em Goethe, portanto, um sentido que declina de qualquer analogia. Não se trata de um signo em lugar de outro, de uma metáfora ou comparação. Simbólico é, para Goethe, o objeto que "parece existir meramente por si mesmo", 
mantendo-se, ainda assim, profundamente significativo. Essa concepção goethiana do simbólico coincide em grande parte com o pressuposto defendido por Moritz de que a criação do Belo artístico dá-se por meio de um processo produtivo, entendido como uma "imitação formadora" [bildende Nachahmung] no sentido de que não se trata de mera reprodução de um objeto existente no mundo natural, mas sim de uma intuição do Belo ideal, perfeito e acabado. Moritz, entretanto, reconhece que a forma artística só pode intuir o Belo de maneira imprecisa e mediata:

A partir do belo real [ideal?], perfeito e acabado, que muito raramente é capaz de se desenvolver de maneira imediata, a Natureza criou de maneira mediata o seu reflexo, por meio de seres nos quais sua imagem é reproduzida de modo tão vívido, que se reflete de encontro a si mesma em sua própria criação. Desse modo, espelhando-se a si mesma por meio desse duplo reflexo, pairando por sobre sua própria realidade, produz uma obra de contornos difusos, mais atraente para os olhos mortais do que ela própria. ${ }^{9}$

Goethe e Moritz entendem o processo de produção do Belo mais elevado (assim como do "simbólico") como resultado de uma capacidade peculiar ao espírito do artista, capaz de intuir a forma ideal em sua completude e perfeição. O processo se dá por meio de uma intuição obscura da alma, que vislumbra, no primeiro momento do processo de imitação formadora do Belo, a obra "como já concluída e perfeita"; as etapas do processo de desenvolvimento gradual do Belo mais elevado estão presentes, no entanto, e apresentam-se,"de uma única vez", nesse momento primeiro da aparição [Entstehung]:

Uma vez que as grandes relações em cuja extensão reside o Belo não pertencem mais à jurisdição da faculdade do pensamento, então o conceito vívido da imitação formadora só pode se dar no sentimento da força da ação que o produz, no primeiro momento da aparição, no qual a obra, como já concluída e perfeita, em obscura intuição [Ahndung], emerge frente à alma de uma única vez, em todos os estágios de sua transformação gradual [...]. ${ }^{10}$

O objeto individual, por sua vez, é apenas o suporte, o foco [Brennpunkt] escolhido no mundo sensível para a manifestação do Belo mais elevado, diz Moritz:

Uma vez que essa representação do Belo mais elevado tem que, necessariamente, fixar-se por meio de alguma coisa, a força formadora [...] elege algo que seja visível, audivel ou palpável [...] para o qual ela possa transferir o brilho do Belo mais elevado em uma medida rejuvenescida. ${ }^{11}$

Neste ponto, é preciso voltar à narrativa das "Confissões da Bela Alma", para quem a questão da fé passa pelo questionamento da mediação dos objetos religiosos. Já em suas primeiras palavras, o relato da Bela Alma apresenta as linhas de força de sua trajetória: a sensibilidade excessiva, a intensificação do pátos e a tendência ao autoisolamento decorrentes de longa doença. Esse estado de coisas é acentuado pela grande curiosidade intelectual da criança e por um verdadeiro "ímpeto de leitura". Dotada de uma sensibilidade exacerbada, a Bela Alma se apresenta, em sua autobiografia, como portadora de uma tendência mórbida ao isolamento e à paixão sensual. O longo período de recolhimento causado pela doença torna introspectiva a alma infantil, fazendo 
com que a Bela Alma, em idade ainda tenra, intensifique os traços de um caráter reflexivo e altamente impressionável, seja pelas histórias fantasiosas, fábulas e romances que ouve e lê, seja por um vago sentimento de religiosidade, que chega mesmo a confundir-se com as outras impressões.

Nessa instância, ainda imprecisa, Deus torna-se seu confidente, uma espécie de "amigo invisível", que a criança mal distingue de qualquer outra espécie de aparição ou manifestação.

Ao longo de seu amadurecimento, a jovem sofre o efeito da primeira paixão erótica, que assoma associada à emoção religiosa. É no convívio com Narcisse, o noivo temporal, que a jovem educará o espírito para o noivo místico, Jesus Cristo. $O$ afeto exclusivo que Ihe dedica, o isolamento frente aos jogos da sociedade e a renovada tendência à autointrospecção, aparentemente decorrentes da paixão romântica, são, na verdade, os prenúncios do afeto religioso. Seu espírito introspectivo leva-a a investigar a natureza desses afetos:

Desenvolviam-se então em minha alma sentimentos de natureza outra, que não contradiziam aqueles. Pois meu amor por Narcisse era conforme com todo o plano da criação e não ia de encontro a nenhum de meus deveres. Não se contradiziam e, no entanto, eram infinitamente distintos. Narcisse era a única imagem que pairava diante de mim, à qual se relacionava todo o meu amor; mas o outro sentimento não se referia a imagem alguma e era inefavelmente agradável..$^{12}$

Estabelece-se aqui a distinção qualitativa entre os dois afetos, afins e ao mesmo tempo distintos. O amor por Narcisse, o noivo terreno, sustenta-se pelo sensível de caráter "imitativo", se nos nortearmos pelo Goethe do ensaio de 1789, "Imitação simples, maneira, estilo"; sua imagem desperta e sustenta o amor que Ihe dedica a Bela Alma. É "a única imagem" que paira a sua frente. $O$ outro afeto, "que não se refere a imagem alguma", prescinde da mediação do sensível, é "inefavelmente agradável".

Esse é o primeiro passo para que a Bela Alma, ao fim de seu desenvolvimento, atinja uma espécie de estado estético no qual poderá até mesmo prescindir dos objetos sensíveis. No episódio de sua conversão pela fé, momento em que finalmente se dá conta, de modo intuitivo, de ter sido tocada pela Graça, a Bela Alma reconhece que a verdadeira fé pode prescindir dos objetos sensíveis, das imagens e mesmo da retórica teológica. Cheia de dúvidas quanto à possibilidade da graça e da salvação dos homens, pergunta-se:

[...] Mas como podemos tomar parte nesse inestimável benefício? Pela fé, responde-nos a Escritura.[...]. Sim, quem poderia descrever o que eu sentia então? Um impulso transportava minha alma para a cruz onde Jesus um dia morreu: um impulso, não posso chamá-lo de outro modo, em tudo semelhante àquele que conduz nossa alma para junto de um amado ausente, provavelmente muito mais essencial e verdadeiro do que supomos. Assim se aproximava minha alma daquele que se fez homem e que morreu na cruz, e nesse instante eu soube o que era a fé. "Isto é a fé!", disse e dei um salto, como que meio assustada. [...] Com tais sentimentos nos abandonam as palavras. Eu 
podia claramente distingui-los de toda fantasia, de qualquer imagem, e no entanto davam a certeza de um objeto ao qual se referiam, como a imaginação, quando nos pinta os traços de um amado ausente. ${ }^{13}$

A experiência da revelação e a certeza de ter sido contemplada pela Graça trazem novamente à superfície a questão da necessidade da manifestação sensível dessa dádiva. Aqui, a manifestação sensível da atribuição da Graça não deixa de estar referida a um objeto, como é necessariamente o caso em Goethe. Entretanto, é preciso ressaltar que tal objeto, distinto de "toda fantasia e toda imagem", assemelha-se a um objeto ideal, porém não abstrato, semelhante aos traços de um "amado ausente".

Evidencia-se um progressivo reconhecimento de que as imagens religiosas servem apenas de suporte fácil ao desejo de fé e estão ligadas antes à força da fantasia e da capacidade de criação de imagens, à Einbildungskraft, do que propriamente à crença. A trajetória da narradora em busca da fé mostra um abandono progressivo da necessidade de transposição dos conteúdos da fé por meio de imagens, canções ou qualquer outro tipo de suporte sensível de caráter alegórico ou retórico. A bela alma abandona não o sensível em si, mas sim os objetos que mediam a relação entre os planos divino e humano por meio de analogias e remissões. A cruz, os cânticos e objetos de culto são abandonados em prol de uma crença que prescinde das imagens, em nome de um afeto autônomo e essencial, em uma palavra, simbólico.

Oh, por que, para falar de tais coisas, temos de empregar imagens que só anunciam situações exteriores? Onde estão ante Ele algo de alto ou de profundo, de escuro ou de claro? Só nós temos um alto e um baixo, um dia e uma noite [...]. ${ }^{14}$.

Sua forma de se relacionar com o plano das coisas divinas dispensa, portanto, a necessidade de referentes empíricos de caráter alusivo. Tal reconhecimento coincide com a defesa, no ensaio de 1789 , do afeto simbólico, que rege uma apresentação autotélica e autônoma.

Evidencia-se aqui um tipo de sensibilidade artística semelhante ao que Moritz entendeu como "intuição obscura" do "Belo mais elevado". Também para a Bela Alma, os objetos do mundo físico são apenas um Brennpunkt, um foco ou um suporte para a mediação de algo que é "inefável" e não experienciável diretamente pelos sentidos. A etapa final do desenvolvimento da Bela Alma compreende uma espécie de fusão entre a sensibilidade religiosa e a emoção estética. Ao tomar contato com a arte formalista do Classicismo weimariano por intermédio da personagem do Tio, grande colecionador de arte, a Bela Alma aprenderá a diferença entre os objetos que Goethe chamou de "objetos naturais", que representam "coisas conhecidas e banais", e aqueles por ele classificados como objetos "ideais", que não devem ser tomados em si mesmos, e que nos afetam, em sua elevação, despidos de todo caráter vulgar e individual. Lembrando a definição linhas acima, os objetos ideais não se tornam artísticos por meio da elaboração mecânica do artista, mas se apresentam a ele já "como um objeto perfeita e completamente construído", produto que são da força de imitação formadora do Belo. 
Em uma crítica declarada aos objetos aos quais até então dedicara sua atenção, a narradora dá-se conta de que, ao mesmo tempo em que estes não serviam à manifestação sensível das coisas divinas, tampouco levavam à educação moral por meio do cultivo do gosto. Lembrando-se do seu passado como cristã admiradora da arte religiosa de caráter meramente imitativo, a Bela Alma confessa-se envergonhada ao recordar que, "entre os cânticos que me haviam edificado, poderia haver alguns de mau gosto, e que as pequenas imagens que se ligavam às minhas idéias espirituais dificilmente teriam encontrado misericórdia aos olhos de meu tio". ${ }^{15}$ De acordo com as concepções estéticas então compartilhadas por Goethe e Schiller e que determinaram as linhas mestras do assim chamado Classicismo de Weimar, a Bela Alma atinge a elevação dos sentidos por meio da música coral, que, segundo a prescrição goethiana, deve ser ouvida pela platéia, mas sem que os cantores sejam vistos em sua atividade, o que poderia desviar a concentração dos ouvintes para detalhes prosaicos e desimportantes. Em vez dos "cânticos piedosos, com os quais as boas almas, frequentemente com a voz roufenha, crêem louvar a Deus", a Bela Alma ouvia agora

uma música que nasce do sentido mais profundo das mais excelentes naturezas humanas que, graças a determinados e exercitados órgãos, volta a falar numa unidade harmoniosa ao melhor e mais profundo sentido do homem, fazendo-o na verdade sentir vivamente naquele momento sua semelhança com Deus. Eram todos cânticos latinos eclesiásticos, que se destacavam como jóias engastadas no anel de ouro de uma sociedade culta, profana, e, sem pretender a assim chamada edificação, elevavam-me de modo mais espiritual e me faziam feliz ${ }^{16}$

Claramente, a Bela Alma reconhece nos "cânticos latinos eclesiásticos" um veículo de caráter não imitativo e ideal, que se opõe a outras formas musicais de caráter "natural": "Agora, pela primeira vez, eu aprendia a diferença que há entre o canto natural, primoroso de um rouxinol e uma 'Aleluia' a quatro vozes, que brota de sensíveis gargantas humanas." ${ }^{17}$

No que diz respeito estritamente às artes plásticas, a Bela Alma apreenderá a relação possível entre a educação moral e a educação estética (tema caro a Schiller, que, como se sabe, acompanhou de perto a composição do romance de Goethe). Para Schiller, a fruição estética que resulta meramente da contemplação do tema dos quadros deve ser recusada. No romance de Goethe, o tio censura a tendência da Bela Alma a se comprazer meramente com o tema dos quadros, o que incita a fantasia e impede a elevação ao estado estético, nos termos de Schiller:

[O tio] dirigiu minha atenção para os diversos quadros pendurados na parede; meus olhos se detinham naqueles cujo aspecto era atraente ou significativo o assunto [...].

- [...]antes descobriremos que aquele cujo espírito anseia por uma [formação] moral tem todas as razões para educar ao mesmo tempo sua mais fina sensibilidade, a fim de não correr o risco de despencar do alto de sua moral, entregando-se às tentações de uma fantasia desregrada e chegando ao caso de degradar sua natureza mais nobre mediante o prazer em brincadeiras insípidas,quando não em algo ainda pior. ${ }^{18}$ 
As palavras do tio despertam na Bela Alma a atenção para a efetiva associação entre a elevação do espírito a partir dos objetos sensíveis. Sua reconciliação com o sensível dáse, pois, por meio da arte, melhor dizendo, por meio da arte programática do Classicismo weimariano, moldada sob os termos da "serena grandeza" [stille Grösse] e "nobre simplicidade" [edle Einfalt], termos usados por Winckelmann para referir-se à arte estatuária grega.

Voltamos agora à elaboração goethiana do conceito de símbolo, que vimos acompanhando desde os esboços de 1770, passando pelo ensaio sobre a "Simples imitação da natureza, maneira, estilo" [Einfache Nachahmung der Natur, Manier, Stil], de 1789, até chegar ao ensaio "Sobre os objetos das artes figurativas" [Über die Gegenstände der bildenden Kunst], de 1797, no qual Goethe denomina símbolo um tipo de significação autotélica e particular, que contém em si, no entanto, o universal. A concepção estética que permeia a reconciliação da Bela Alma com o sensível é antes um desdobramento dessa concepção estética em progresso. No ensaio de 1789, Goethe propusera uma relação hierárquica entre os três elementos do título, no qual o estilo "caracteriza o mais alto grau já alcançado pela arte ou a ser ainda alcançado por ela". O estilo nos "conduz até o sagrado"19, "eleva o indivíduo ao ponto mais alto que o gênero pode alcançar, sendo essa a razão pela qual grandes artistas aproximam-se uns dos outros nas suas melhores obras". ${ }^{20}$ Essa ordenação ao geral não acontece, no entanto, por meio de uma abstração, mas sim, como aponta Sorensen (1963), por meio da compreensão do que é "típico e do imutável nas coisas" (grifo meu). O ensaio de 1789 sobre a "Simples imitação da natureza, maneira, estilo" prepara, na concepção de "estilo", aquilo que o Goethe de 1797 entenderá sob o termo "símbolo": a possibilidade de contemplar o universal mesmo no particular, no objeto e na experiência. Em termos de fruição estética, e de acordo com o Schiller das Cartas sobre a educação estética, toda a determinabilidade é banida, em prol do afeto ideal e autônomo.

O acompanhamento da trajetória da Bela Alma permite que se vislumbre seu aperfeiçoamento espiritual em direção a uma crença autônoma e individualíssima, capaz de prescindir mesmo da retórica teológica e dos suportes mais doutrinários da fé. Paralelamente, essa mesma trajetória tornará possível o acesso às bases do pensamento estético de Goethe à época, nesse momento muito próximo de Moritz e Schiller, e, portanto, indiretamente familiarizado com o kantismo de ambos.

Ao prescindir da retórica teológica e dos suportes físicos da fé no mundo sensível, a Bela Alma realiza, no romance de Goethe escrito entre 1795 e 1796, aquilo que Goethe havia elaborado nos anos de convivência com Moritz em Roma. Em uma palavra, a passagem para a maturidade estética do Classicismo Weimariano. 
${ }^{1}$ GRAY, 1952, p. 265 apud SORENSEN, B. A. Symbol und Symbolismus in den ästhetischen Theorien des 18. Jahrhunderts und der deutschen Romantik. Kopenhagen: Munskgaard, 1963, p. 86.

2 "Die Kunst ist nicht anders als das Licht der Natur". GOETHE, J. W. Werke. Herausgegebenen im Auftrage der Großherzogin Sophie von Sachsen. Weimar: Hermann Böhlau, 1887-1919 143v. Böhlaus Verlag, vol. 37, p. 87.

3 "Sie [die Form] ist für allemal das Glas, wodurch wir die heiligen Strahlen der verbreiteten Natur an das Herz der Menschen zum Feuerblick sammeln. Aber das Glas! Wem's nicht gegeben wird, wird's nicht erjagen". Ibidem, v. 36, p. 116.

${ }^{4}$ GOETHE, J. W. Escritos sobre arte. Introdução, tradução e notas de Marco Aurélio Werle. São Paulo: Humanitas/Imprensa Oficial, 2008, p. 84.

${ }^{5}$ Ibidem, p. 83.

${ }^{6}$ GOETHE, J. .Werke. Herausgegebenen im Auftrage der Großherzogin Sophie von Sachsen, op. cit., v. 47 , p. 92.

${ }^{7}$ GOETHE, J. W. Escritos sobre arte, op. cit., pp. 84-85, grifo meu.

8 Ibidem, p. 85.

${ }^{9}$ Von dem reellen und vollendenten Schönen also, was unmittlebar sich selten entwickeln kann, schuf die Natur doch mittelbar den Wiederschein durch Wesen in denen sich ihr Bild so lebhaft abdrückte, dass es sich ihr selber in ihre eigene Schöpfung wieder entgengewarf. - Und so brachte sie, durch diesen verdoppelten Widerschein sich in sich selber spiegelnd, über ihre Realität schwebend und gaucklend, ein Blendwerk hervor, das für sterbliches Auge noch reizender, als sie selber ist. (MORITZ, K. P. Die Signatur des Schönen und andere Schriften zur Begründung der Autonomieästhetik. Hamburg: Philo Phine Arts, 2009, p. 42)

10 "Da nun aber jene grossen Verhältnisse, in deren völligen Umfange eben das Schöne liegt, nicht mehr unter das Gebiet der Denkkraft fallen; so kann auch der lebendige Begriff von der bildenden Nachahmung des Schönen, nur im Gefühl der thätigen Kraft, die es hervorbringt, im ersten Augenblick der Entstehung statt finden wo das Werk, als schon vollendet, durch alle Grade seines allmählichen Werdens, in dunkler Ahndung, auf einmal vor die Seele tritt [...]”. Ibidem, p. 46.

11 "Weil nur aber dieser Abdruck des Höchsten Schönen nothwendig an etwas haften muss, so wählt die bildende Kraft [...] irgend einen sichtbaren, hörbaren, oder doch [...] fassbaren Gegenstand, auf den sie den Abglanz des höchsten Schönen im verjüngenden Maasstabe überträgt". Ibidem, p. 45.

12 GOETHE, J. W. Os anos de aprendizado de Wilhem Meister. Tradução de Nicolino Simone Neto. São Paulo: Ensaio, 1994, p. 367, grifo meu.

${ }^{13}$ Ibidem, p. 385, grifo meu.

${ }^{14}$ Ibidem, grifo meu.

${ }^{15}$ Ibidem, p. 397.

${ }^{16}$ Ibidem, p. 399.

17 Ibidem, p. 393, grifo meu.

${ }^{18}$ Ibidem, p. 397, grifo meu.

${ }^{19}$ GOETHE, J. W. Werke. Herausgegebenen im Auftrage der Großherzogin Sophie von Sachsen, op. cit.. v. 33, p. 58.

${ }^{20}$ Ibidem, p. 253. 